\title{
Magnetic Structures and Properties of $\mathrm{FeP}_{1-x} \mathbf{A s}_{x}$
}

\author{
KARI SELTE, a ARNE KJEKSHUS, a TOR A. OFTEDAL a and ARNE F. ANDRESEN b
}

aKjemisk Institutt, Universitetet i Oslo, Blindern, Oslo 3, Norway and ${ }^{\mathrm{b}}$ Institutt for Atomenergi, Kjeller, Norway

The pseudo-binary $\mathrm{FeP}-\mathrm{FeAs}$ system has been investigated by X-ray and neutron diffraction, magnetic susceptibility, and magnetization measurements. FeP and FeAs are completely soluble in each other, an MnP type structure with random distribution of $P$ and $A s$ being found independent of temperature and composition. The double $c$ axis helimagnetic ordering in $\mathrm{FeP}$ and $\mathrm{FeAs}$ extends into the P-rich region (at least to $x=0.10$ ). The results are discussed in relation to an isotropic exchange interaction model.

Among the nine binary monopnictides of the $3 d$ elements which take the MnP type structure, helimagnetic ordering has been reported for $\mathrm{CrAs},{ }^{1-3} \mathrm{MnP},{ }^{4,5} \mathrm{FeP},{ }^{6}$ and $\mathrm{FeAs} .{ }^{7}$ In order to gain further insight into the factors which determine this behaviour, attention is presently focussed on ternary derivatives of these compounds. Low temperature neutron diffraction studies of $\mathrm{Cr}_{1-t} \mathrm{Mn}_{t} \mathrm{As}^{1} \mathrm{Mn}_{1-t} \mathrm{Fe}_{t} \mathrm{As}^{,}{ }^{8}$ and $\mathrm{MnAs}_{1-x} \mathrm{P}_{x}{ }^{9,10}$ have so far demonstrated that this angle of approach may be rather fruitful.

In addition there are also scattered investigations on the magnetic properties of $\mathrm{V}_{1-t} \mathrm{Fe}_{t} \mathrm{As},{ }^{11}$ $\mathrm{Cr}_{1-t} \mathrm{Fe}_{t} \mathrm{As},{ }^{12} \quad \mathrm{Mn}_{1-t} \mathrm{Fe}_{t} \mathrm{P},{ }^{13-16} \quad \mathrm{Mn}_{1-t} \mathrm{Co}_{t} \mathrm{P},{ }^{17}$ $\mathrm{Fe}_{1-t} \mathrm{Co}_{t} \mathrm{P},{ }^{16}$ and $\mathrm{FeP}_{1-x} \mathrm{As}_{x},{ }^{16}$ of which $\mathrm{Cr}_{1-t} \mathrm{Fe}_{t} \mathrm{As}, \mathrm{Mn}_{1-t} \mathrm{Fe}_{t} \mathrm{P}$, and $\mathrm{FeP}_{1-x} \mathrm{As}_{x}$ appear to be of particular interest. The present paper concerns the magnetic structures and properties of $\mathrm{FeP}_{1-x} \mathrm{As}_{x}$. The relevant properties of $\mathrm{FeP}^{6}$ and $\mathrm{FeAs}^{\text {? }}$ (i.e. relatively short spiral periods, small magnetic moments, and low Néel temperatures) indicate that such a study may present challenging experimental problems.

\section{EXPERIMENTAL}

The binary compounds FeP and FeAs were prepared by heating weighed quantities of the elements [99.99 \% Fe (Johnson, Matthey \& Co.; turnings from rods), $99.999 \% \mathrm{P}$ and $99.9999 \%$ As (Koch-Light Laboratories)] in evacuated, sealed silica tubes as described in Refs. 7, 18. Ternary $\mathrm{FeP}_{1-x} \mathrm{As}_{x}$ samples of desired compositions were prepared from appropriate proportions of FeP and FeAs, by means of three annealings at $850{ }^{\circ} \mathrm{C}$ interrupted by intermediate crushings. The samples were finally cooled to room temperature over a period of 3 days.

Experimental details concerning X-ray and neutron diffraction (including data reduction), magnetic susceptibility, and magnetization measurements have been reported earlier. ${ }^{7}$

\section{RESULTS}

(i) Chemical crystal structure. The orthorhombic unit cell dimensions of $\mathrm{FeP}_{1-x} \mathrm{As}_{x}$ (as determined from room temperature $\mathrm{X}$-ray powder photographs) are shown in Fig. 1. as functions of the composition parameter $x$. FeP and $\mathrm{FeAs}$ exhibit complete, mutual solubility, as evidenced by the continuous variation in all unit cell dimensions with $x$. The various curves in Fig. 1 follow Vegard's Law to a good approximation over the entire solubility range. A possible extension of the homogeneity range of $\mathrm{FeP}_{1-x} \mathrm{As}_{x}$ to metal/non-metal (atomic) ratios different from 1.00 has not been examined for $x \neq 0$ and 1 (cf. Refs. 18, 19).

The X-ray data show an MnP type structural arrangement for $0 \leq x \leq 1$ at room temperature. The lack of additional superstructure reflections in these data confirms that the substituted atoms are randomly distributed over the nonmetal sub-lattice.

Samples with $x=0.10,0.50$, and 0.90 were chosen for neutron diffraction examinations at $4.2,80$, and $293 \mathrm{~K}$. The final values for the

Acta Chem. Scand. A 28 (1974) No. 9 


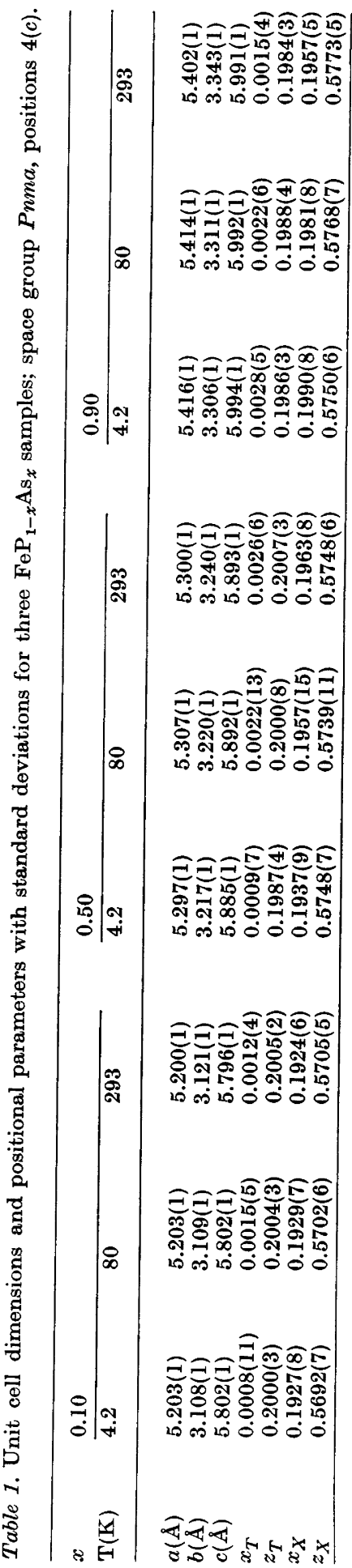

Acta Chem. Scand. A 28 (1974) No. 9 


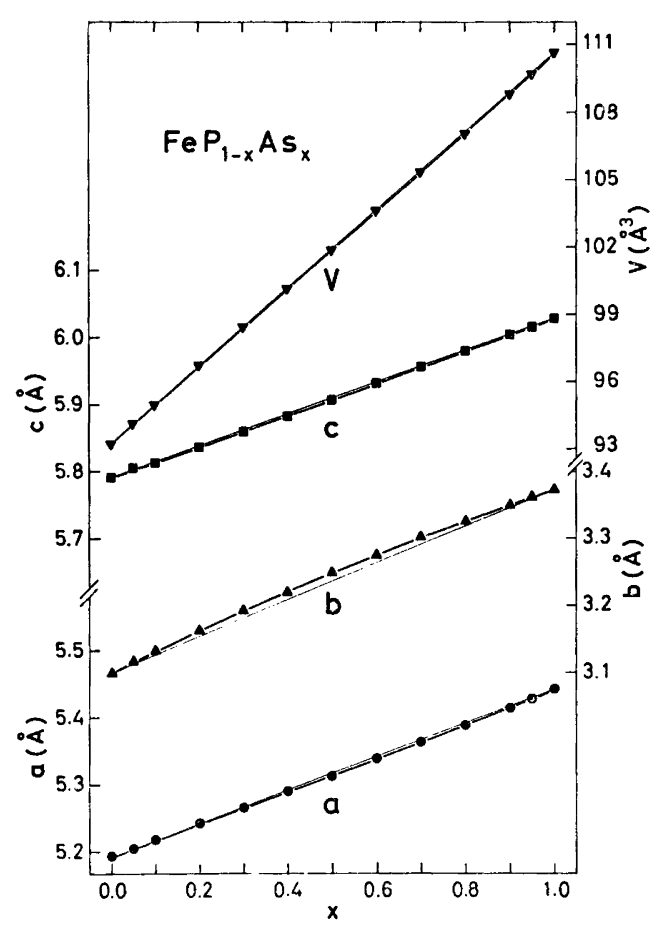

Fig. 1. Unit cell dimensions of the ternary solid solution series $\mathrm{FeP}-\mathrm{FeAs}$ as functions of composition.

least squares profile refined parameters are listed in Table 1, magnetic reflections (vide infra) being excluded at 4.2 and $80 \mathrm{~K}$ for $x=0.10$. The variation of the positional parameters with composition at room temperature is illustrated in Fig. 2. The figure shows, in accordance with expectation, continuous changes

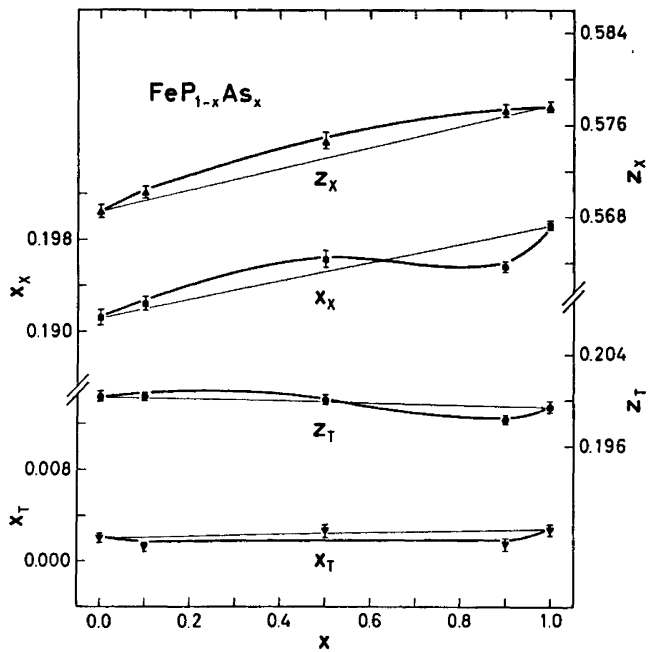

Fig. 2. Positional parameters $x$ and $z$ for metal $(T)$ and non-metal $(X)$ as functions of composition at room temperature. Data for $\mathrm{FeP}$ and FeAs are quoted from Refs. 18, 20.

in all these variables with composition. However, too much confidence cannot be put on details of the diagram.

The same samples were subjected to a high temperature X-ray diffraction study in order to establish whether the phase undergoes a crystallographic transformation to the NiAs type structure. No such transformation was observed, and the results shown in Fig. 3, are accordingly in agreement with the findings for $\mathrm{FeAs.}{ }^{7}$ The relative linear expansion coefficients given on the diagram, are also seen to exhibit a continuous variation with $x$.
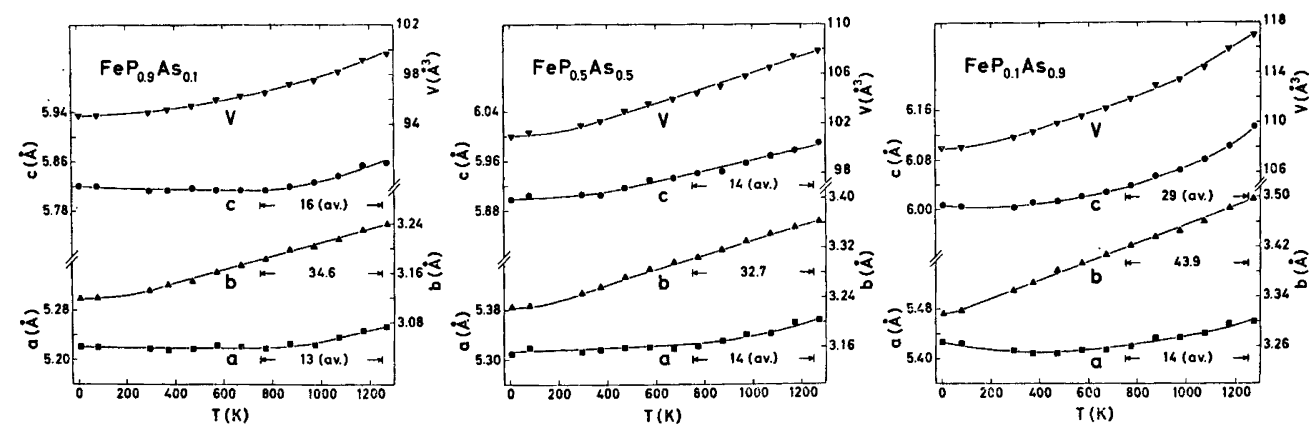

Fig. 3. Unit cell dimensions of three $\mathrm{FeP}_{1-x} \mathrm{As}_{x}$ samples as functions of temperature. The relative expansion coefficients $\alpha_{a}\left[=\left(a_{\mathrm{T}}-a_{\mathrm{T}}{ }^{\prime}\right) / a_{300}\left(\mathrm{~T}-\mathrm{T}^{\prime}\right)\right], \alpha_{b}, \alpha_{c}$ multiplied by $10^{6} \mathrm{~K}$ are positioned below the appropriate curves. Corresponding triplet for $\mathrm{FeAs}^{7}$ is 11 (av.), 44 (av.), 22 (av.).

Acta Chem. Scand. A 28 (1974) No. 9 


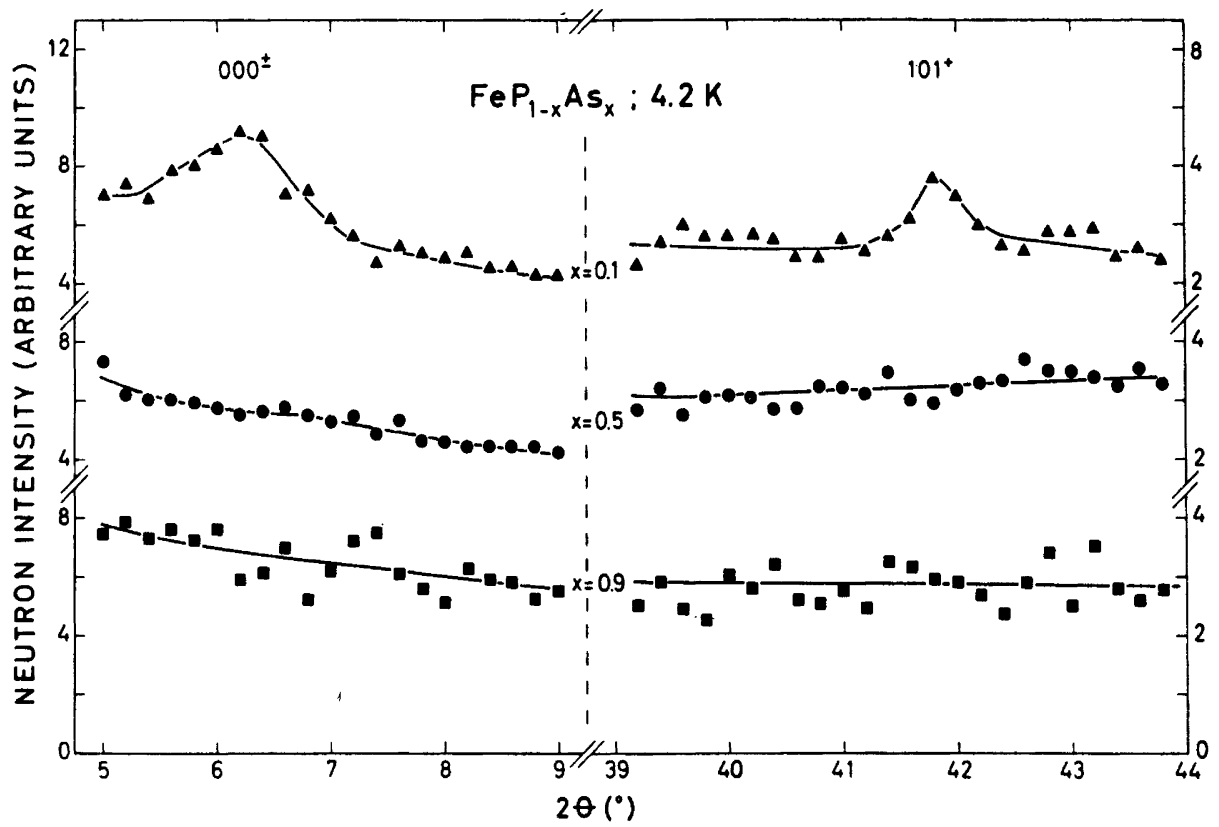

Fig. 4. Partial neutron diffraction diagrams for samples with $x=0.10,0.50$, and 0.90 in $\mathrm{FeP}_{1-x} \mathrm{As}_{x}$.

(ii) Magnetic susceptibility and magnetization. Magnetic susceptibility measurements of some 15 samples covering the entire composition range of $\mathrm{FeP}_{1-x} \mathrm{As}_{x}$ were carried out between 80 and $\sim 1000 \mathrm{~K}$. Apart from the samples with $x=0.00,0.10$, and 1.00 ferrimagnetic impurities originating from traces of $\mathrm{Fe}_{3} \mathrm{O}_{4}$ rendered the results of these efforts practically worthless. Similar difficulties were experienced in earlier studies of polycrystalline samples of $\mathrm{FeP}{ }^{18}$ and $\mathrm{FeAs}$, the latter compound being especially exposed to such impurification. (This difficulty was avoided in studies of $\mathrm{Mn}_{1-t} \mathrm{Fe}_{t} \mathrm{As}^{8}$ and $\mathrm{V}_{1-t} \mathrm{Fe}_{t} \mathrm{As}^{11}$ where, on the other hand, other (neither ferro- nor ferrimagnetic) oxides are formed.)

Surprisingly, the sample $\mathrm{Fe} \mathrm{P}_{0.90} \mathrm{As}_{0.10}$ gave no indication of the oxide impurity. The reciprocal magnetic susceptibility versus temperature curve of this sample shows a similar characteristic to that of $\mathrm{FeP} \cdot{ }^{18}$ Curie-Weiss' Law is satisfied between 200 and $750 \mathrm{~K}$ with $\theta=-820 \pm 50$ $\mathrm{K}, \mu_{\mathrm{P}}=1.8 \pm 0.1 \mu_{\mathrm{B}} / \mathrm{Fe}$ atom, which gives a spin quantum number $S=0.53 \pm 0.05$ according to the "spin only" approximation.

(iii) Magnetic structure. $\mathrm{FeP}$ and FeAs have previously ${ }^{6,7}$ been found to exhibit helimagne- tism below Néel temperatures of $125 \pm 1$ and $77 \pm 1 \mathrm{~K}$, respectively. Their helimagnetic arrangements are of the double $c$ axis spiral type also observed for $\mathrm{CrAs},{ }^{1-3} \mathrm{Cr}_{1-t} \mathrm{Mn}_{t} \mathrm{As},{ }^{1}$ and MnP.4,5 The parameters specifying the spirals are $\mu_{\mathrm{Fe}}\left(=2 S_{\mathrm{Fe}}\right)=0.41 \mu_{\mathrm{B}}$ (av.), $\tau=0.20 \times 2 \pi \mathrm{c}^{*}$ and $\varphi_{1,2}=168.8^{\circ}$ for $\mathrm{FeP}$ at $4.2 \mathrm{~K}$ and $\mu_{\mathrm{Fe}}=$ $0.5 \pm 0.1 \mu_{\mathrm{B}}, \tau=0.375 \times 2 \pi \mathrm{c}^{*}$, and $\varphi_{1,2}=-140 \pm$ $10^{\circ}$ for $\mathrm{FeAs}$ at $12 \mathrm{~K}$, moments being assumed at right angles to the spiral axis in both cases.

The neutron diffraction diagrams of the samples with $x=0.10,0.50$, and 0.90 at $4.2 \mathrm{~K}$ show extra reflections of purely magnetic origin only for that with $x=0.10$. The search for a $000^{ \pm}$satellite, characteristic of the above helimagnetic arrangement, was performed with a relatively long neutron wavelength $(2.4625 \AA)$ and a three-axes spectrometer arrangement in order to obtain a good resolution in the low angle region. Selected regions of the neutron diffraction diagrams for the three samples are shown in Fig. 4, where the presence of the $000^{ \pm}$ and $101^{+}$satellites is evident only for $x=0.10$.

On the assumption of an isostructural, magnetic arrangement in $\mathrm{FeP}, \mathrm{FeP}_{\mathbf{0 . 9 0}} \mathrm{As}_{0.10}$, and $\mathrm{FeAs}$, the evaluation of the spiral parameters followed the procedure outlined in Refs. 2, 7.

Acta Chem. Scand. A 28 (1974) No. 9 
The derived values for these parameters are $\mu_{\mathrm{Fe}}=0.42 \pm 0.02 \mu_{\mathrm{B}}, \tau=0.254 \times 2 \pi \mathrm{c}^{*}$, and $\varphi_{1,2}=$ $155 \pm 5^{\circ}$ at $4.2 \mathrm{~K}$. From the temperature dependence of the integrated intensity of the 101satellite, the Néel temperature was determined as $\mathrm{T}_{\mathrm{N}}=96 \pm 5 \mathrm{~K}$. The normalized integrated intensity of this reflection is shown in Fig. 5 as a function of reduced temperature, the Brillouin curve for $S=1 / 2$ being indicated for the purpose of comparison.

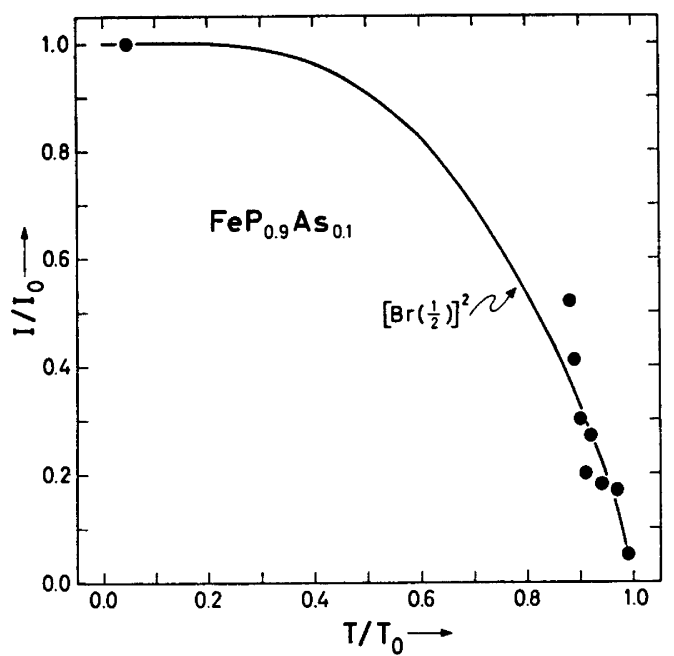

Fig. 5. Normalized intensity versus reduced temperature for $101^{-}$of $\mathrm{FeP}_{0.90} \mathrm{As}_{0.10^{-}}$.

Small magnetic contributions to nuclear peaks are usually difficult to detect. Hence, it is impossible on the basis of the present data to substantiate or reject the hypothesis of a small ferromagnetic moment with $\mu_{\mathrm{Fe}}<0.5 \mu_{\mathrm{B}}$ in the samples with $x=0.50$ and 0.90 at $4.2 \mathrm{~K}$. A number of different orientations of the moment have been tried, but no significant improvements in the reliability factor was obtained.

\section{DISCUSSION}

The number of unpaired electrons observed for $\mathrm{FeP} \mathrm{P}_{0.90} \mathrm{As}_{0.10}$ fits nicely in with those for $\mathrm{FeP}$ and $\mathrm{FeAs}$. Also the other spiral parameters fall between those for the binary compounds (vide supra). This finding provokes a discussion of the absence of helimagnetism for the samples with $x=0.50$ and 0.90 .

Acta Chem. Scand. A 28 (1974) No. 9
The exchange interactions in compounds with the MnP type structure have recently been treated by Kallel et al. ${ }^{21}$ Although these authors do not present the complete solution of this interaction problem, their treatment of the $c$ axis double helimagnetic and ferromagnetic modes is exhaustive. For the present purpose only the most realistic solution, the isotropic case with four exchange parameters, $J_{4,1}, J_{1,2}, J_{1,1}$, and $J_{1,4}$, is considered. (The atoms and, hence, the exchange parameters follow the numbering in Refs. 2, 7.) According to Kallel et al. ${ }^{21}$ the stability condition for the ferromagnetic mode is $4 U V+U+V>0$

and for the $c$ axis double helimagnetic mode

$4 U V+U+V<0$ or

$-4 U V+U+V>0$

where $U=J_{4,1} / J_{1,2}$ and $V=J_{1,4} / J_{1,2}$. Numerical values for $U$ and $V$ are calculated on the basis of the observed phase angles in $\mathrm{FeP}$, $\mathrm{FeP}_{0.90} \mathrm{As}_{0.10}$, and $\mathrm{FeAs}$ and are shown in Fig. 6 in

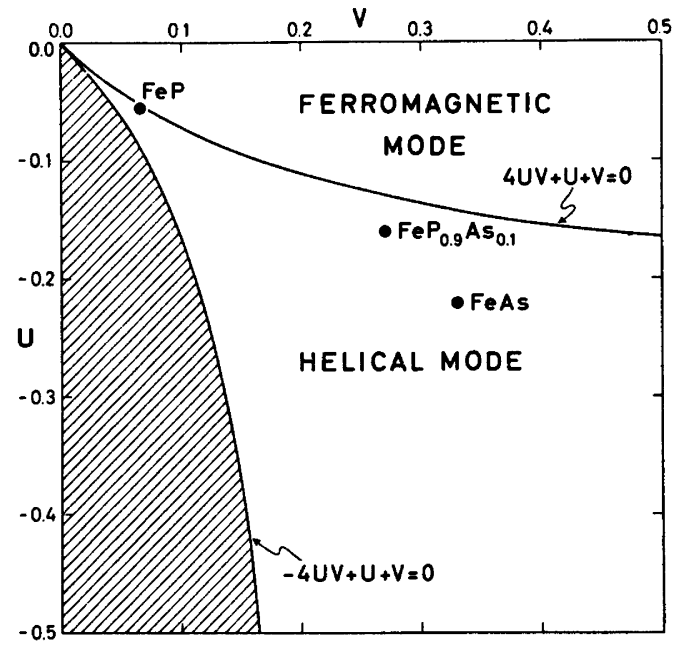

Fig. 6. Relevant quadrant of $U, V$ stability diagram for helimagnetic and ferromagnetic modes in $\mathrm{MnP}$ type compounds according to isotropic model of Kallel et al..$^{21}$

relation to the above stability conditions. The closeness of the three points to the borderline between helimagnetic and ferromagnetic ordering leads one to suggest that the corresponding points for $\mathrm{FeP}_{0.50} \mathrm{As}_{0.50}$ and $\mathrm{FeP}_{0.10} \mathrm{As}_{0.90}$ may be located on the ferromagnetic side of the borderline. This would provide a simple and 
natural explanation of the data at hand, but can unfortunately not be confirmed.

In order to elucidate these and other associated problems further, work on $\mathrm{V}_{1-t} \mathrm{Cr}_{t} \mathrm{As}$, $\mathrm{V}_{1-t} \mathrm{Mn}_{t} \mathrm{As}, \mathrm{CrP}_{1-x} \mathrm{As}_{x}, \mathrm{Cr}_{1-t} \mathrm{Fe}_{t} \mathrm{As}, \mathrm{Cr}_{1-t} \mathrm{Co}_{t} \mathrm{As}$, $\mathrm{Mn}_{1-t} \mathrm{Co}_{t} \mathrm{As}$, and $\mathrm{Fe}_{1-t} \mathrm{Co}_{t} \mathrm{As}$ is now in progress.

\section{REFERENCES}

1. Kazama, N. and Watanabe, H. J. Phys. Soc. Jap. 30 (1971) 1319.

2. Selte, K., Kjekshus, A., Jamison, W. E., Andresen, A. F. and Engebretsen, J. E. Acta Chem. Scand. 25 (1971) 1703.

3. Boller, $\mathrm{H}$. and Kallel, A. Solid State Commun. 9 (1971) 1699.

4. Felcher, G. P. J. Appl. Phys. 37 (1966) 1956.

5. Forsyth, J. B., Pickart, S. J. and Brown, P. J. Proc. Phys. Soc. 88 (1966) 333.

6. Felcher, G. P., Smith, F. A., Bellavance, D. and Wold, A. Phys. Rev. B 3 (1971) 3046.

7. Selte, K., Kjekshus, A. and Andresen, A. F. Acta Chem. Scand. 26 (1972) 3101.

8. Selte, K., Kjekshus, A. and Andresen, A. F. Acta Chem. Scand. A 28 (1974) 61.

9. Hall, E. L., Schwartz, L. H., Felcher, G. P. and Ridgley, D. H. J. Appl. Phys. 41 (1970) 939.

10. Schwartz, L. H., Hall, E. L. and Felcher, G. P. J. Appl. Phys. 42 (1971) 1621.

11. Selte, K., Kjekshus, A. and Oftedal, T. A. Acta Chem. Scand. A 28 (1974) 803.

12. Kazama, N. and Watanabe, H. J. Phys. Soc. Jap. 30 (1971) 578.

13. Roger, A. and Fruchart, R. C. R. Acad. Sci. $C 264$ (1967) 508.

14. Bonnerot, J., Fruchart, R. and Roger, A. Phys. Lett. A 26 (1968) 536.

15. Sénateur, J.-P., Roger A., Fruchart, R. and Chappert, J. C. R. Acad. Sci. C 269 (1969) 1385.

16. Maeda, Y. and Takashima, Y. J. Inorg. Nucl. Chem. 35 (1973) 1219.

17. Jones, E. D. Phys. Rev. 158 (1967) 295.

18. Selte, K. and Kjekshus, A. Acta Chem. Scand. 26 (1972) 1276.

19. Selte, K. and Kjekshus, A. Acta Chem. Scand. 23 (1969) 2047.

20. Selte, K. and Kjekshus, A. Acta Chem. Scand. 27 (1973) 1448.

21. Kallel, A., Boller, H. and Bertaut, E. F. J. Phys. Chem. Solids 35 (1974) 1139.

Received May 9, 1974. 